\title{
Leader histories and threat
}

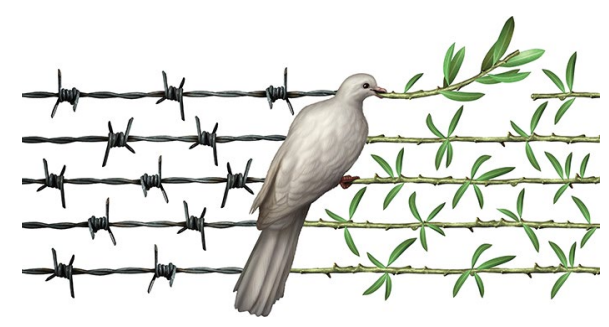

Credit: Brain light/Alamy Stock Photo

A longstanding debate revolves around the relative roles that political conditions and the personalities, experiences, and worldviews of individuals play in shaping world politics. Do leaders matter?

A study by Michael Horowitz of the University of Pennsylvania and colleagues at the University of Virginia sheds light on this question by examining the relationship between the life experiences of political leaders and their propensity to make threats. By analysing the career trajectories and dispute histories of world leaders over time, they find that leaders who had military careers before political office are more likely to issue threats and engage in international disputes, but these threats are also likely to fail. However, leaders whose military experience included combat issue fewer threats that are more likely to be successful. Leaders who previously engaged in armed rebellion have threat patterns similar to career military leaders, suggesting that these histories can produce greater risk tolerance and an associated willingness to threaten others. Direct experience with combat tempers this optimism about the utility of force and leads to more selective and successful threats.

The results suggest that the experience of war shapes leaders in ways that matter for international diplomacy and conflict.

Aisha Bradshaw

Published online: 20 December 2018 https://doi.org/10.1038/s41562-018-0514-1 